\title{
Defining Intentionality
}

\author{
D. Seron
}

Conference “The Phenomenal Content of Perception”, Liège, Feb 2015.

My talk will be about Franz Brentano’s theory of intentionality. My aim is to propose a somewhat unconventional reading of the Psychology from an Empirical Standpoint, on the basis of which I will then offer some exploratory reflections on intentionality and experience, at the most general level.

Some concepts are tools to solve problems, and some are just problems. For example, Aristotle developed his concept of accident in order to explain how a thing can acquire or lose properties; Kant designed his concept of schema in order to solve the problem of how pure concepts relate to sensory experience, and so on. It is quite otherwise with the concept of intentionality, which seems to be no more than an umbrella term for a range of facts that, for one reason or another, are viewed as anomalies. For example, intentionality has something to do with referential opacity and failure of substitutivity, but it is unclear what these two features have in common. This is why intentionality sometimes sounds like a magical word. You observe that some entities violate Leibniz's law or the law of excluded middle — but you shouldn't worry about that: it’s normal, it’s just intentionality!

What I'd like to suggest here is that the problem, or problems, of intentionality shouldn't be taken too seriously. For example, it may seem puzzling that one group of four things is both one and four, that is, both one and not one, or both four and not four. But our intuition is that the issue is not real, that it is a grammatical artifact.

As I will argue, “intentionality” might be just a convenient yet not unambiguous word for denoting other things which are less or not problematic. There are many possible ways to 
understand this idea. One of them is to say that intentionality is not a primitive term, and that it needs to be defined in terms of something else.

Of course, this is nothing new. There was a time, not so long ago, when most philosophers of mind made it their primary business to "naturalize" intentionality, that is to say, to define it in causal or functional terms, hence as a physical entity as are computer programs and biological functions. Here are some samples of such definitions (they are taken from Alex Byrne [Intentionality 408-409]):

\title{
Causal covariational theories
}

(Dretske 1981, Stalnaker 1984, Fodor 1990)

A belief state $\mathrm{S}$ represents that $\mathrm{p}$ (that is, has propositional content that $\mathrm{p}$ ) iff the fact that $\mathrm{p}$ would cause a subject to be in S.

\section{$\underline{\text { Teleological theories }}$}

(Papineau 1987, Millikan 1993, Dretske 1995)

\begin{abstract}
A belief state $\mathrm{S}$ represents that $\mathrm{p}$ iff in conditions in which a subject's cognitive system is functioning as it is designed to function by evolution, the subject would be in $\mathrm{S}$ when and only when it is the case that $\mathrm{p}$.

Functional role theories

(Harman 1999)

A two-place sentence connective * means and iff the acceptance of sentence $\mathrm{P}$ and sentence $\mathrm{Q}$ is disposed to cause the acceptance of the sentence $\mathrm{P} \wedge{ }^{*} \wedge \mathrm{Q}$ (i.e. $\mathrm{P}$ concatenated with * concatenated with $Q$ ), and the acceptance of $P \wedge * \wedge Q$ is disposed to cause the acceptance of $\mathrm{P}$ and the acceptance of $\mathrm{Q}$.
\end{abstract}

Things have changed recently. Some authors endorsed what Galen Strawson (Mental Reality 208) calls the "no-problem thesis". On this view, the efforts to naturalize intentionality have been successful, with the result that, although intentionality remains a problem for scientists, 
it is no longer a problem for philosophers. The real philosophical problem, the "hard problem”, now, is phenomenal consciousness.

I think a similar view underlies many of the currently popular representational theories of consciousness. The overall idea behind these theories seems to be as follows. Philosophers, it is argued, have now to turn to the "hard problem" just because intentionality has ceased to be a philosophical problem. But this does not mean that intentionality has become irrelevant. Instead, philosophers should now use intentionality as a primitive term to define other things, especially phenomenal consciousness. To put it otherwise: you think the idea of an objective theory of subjective experience is somehow self-contradictory, but we may try to define consciousness in terms of intentionality. For intentionality is now naturalized. As a consequence, if we succeed, consciousness will thereby be naturalized as well, and thus phenomenal consciousness will cease to be a philosophical problem.

This strategy I will call the "naturalistic strategy". I think it is deeply unsatisfactory, but I won't discuss it directly. What I propose is to consider another approach to consciousness and intentionality, which is the exact converse of the naturalistic strategy and which I will call the “empiricist” or "phenomenological strategy”. This empiricist strategy is typically the one Brentano followed in 1874 in his Psychology from an Empirical Standpoint.

Psychology from an Empirical Standpoint is first of all a treatise in epistemology, whose only purpose is to provide foundations for scientific, that is, empirical psychology. This project has two aspects. First, the book is about empirical knowledge. Second, the knowledge in question is psychological knowledge.

In Brentano’s view, for a science to be “empirical” means that its objects are not substances, but phenomena and only phenomena. So empirical psychology is not the science of the soul, that is, of mental substances, but the "science of mental phenomena". Empirical natural science is not the science of bodies, that is, of physical substances, but it is the "science of physical phenomena”. The view Brentano rejects is not only the view that psychology and physics should be purely rational or speculative, but also some Lockean form of empiricism, namely the view that science relates to substances indirectly, through their phenomenal affections or causal effects.

The second question was about psychological science in particular. Like Aristotle, Brentano thought that sciences differ from each other by their objects. In other words: defining 
psychology means defining the mental. But not the mental in general. Since science in general must refer to phenomena and only phenomena, the question is, What is a mental phenomenon? Within the flow of experience, some phenomenal data have distinctive features that suffice to qualify them as “mental”. And as you know, according to Brentano, intentional directedness is such a feature.

This suggests, at the very least, that Brentano does not use the notion of intentionality to define phenomenal consciousness or experience. Rather, intentionality is a phenomenal property, something that appears in your mind, that is, something such that phenomenal experience enters into its definition. That's why I said that Brentano’s approach is the converse of the naturalistic approach. His purpose is not to define consciousness through intentionality, but conversely to define intentionality through consciousness. In other words, what he proposes is not a representational theory of consciousness, but a phenomenological theory of intentionality.

As you probably know, Brentano never used the word "intentionality”. He used the adjective "intentional”, which for the late scholastics was somehow synonymous with "appearing in the mind", in some specific sense. And it is noteworthy that Brentano uses the word "intentional" interchangeably with the word “phenomenal” (see Brentano 1973: 129; Engl. transl. 92).

What I am going to do now is to outline what I take to be Brentano’s phenomenological definition of intentionality. I will discuss some aspects of it which I think are more significant, and finally I will conclude by briefly considering five advantages of the empiricist over the naturalistic approach and of Brentano’s empiricism over other forms of empiricism.

\section{A phenomenological definition of intentionality}

Most importantly, for Brentano as for many other empiricist philosophers of his time, defining is not merely clarifying what a word means and how you have to use it, but also and foremost to indicate what you actually refer to when you use it. Brentano's reasoning is as follows. Since psychology is the science of mental phenomena and mental phenomena are essentially representational, it is to be expected that most of the psychologist's judgments will be 
expressible by sentences with intentional verbs, say, by sentences of the form "A represents B". Accordingly, the question of what are the objects of psychology is equivalent to the question of what sentences of the form “ $A$ represents $B$ ” refer to. For example, a psychologist affirms that a subject $A$ (she or someone else) imagines Pegasus. The question is, What are the objects of this judgment? What does it refer to? When you accept it as true that $A$ imagines Pegasus, are you committed to the existence of Pegasus? Or to the existence of $A$ ? Or to neither?

In some sense, this is a question of grammar. Another way to express the same idea is to say that intentional sentences are referentially delusive and need to be rephrased. Defining what an intentional fact is requires rephrasing sentences of the form “ $A$ represents $B$ ” in such a way as to make apparent the objects actually referred to.

Here is what I believe to be Brentano's rephrasing of “ $A$ represents $B$ ” and hence his definition of intentionality:

(INT) For all $x, x$ is a representation of $A$ iff $x$ appears and $x$ (really) exists and $A$ does not (really) exist and $A$ appears in $x$.

As I will show in the course of this presentation, all conditions on the right-hand side of the biconditional are explicitly contained in the 1874 Psychology.

What is important for now is that the primitive terms in the defining sentence are “... appears”, “... exists”, and the pheno-mereological relation “... appears in...”. The general idea is that $x$ 's representing $A$ means this: something appears in the mind in such a way that something else that does not exist, a "mere appearance”, appears in it.

Note that the letter $A$ on the left-hand side creates a problem because it can be neither a constant nor a bound variable in the usual sense. This problem is simply one variant of the socalled "problem of intentionality", which is due to the fact that " $x$ represents $y$ " does not imply "there exists a $y$ such that $x$ represents $y$ ". In our definition, the proposition "there exists 
an $A$ such that $x$ represents $A$ " is inconsistent with the condition " $A$ does not exist" on the right-hand side of the formula. But more on this later.

\section{2. $x$ and $A$ appear}

Let's begin with the two clauses " $x$ appears" and " $A$ appears”. We will for now set the relation “in $x$ ” aside, and return to it later.

" $x$ and $A$ appear" is synonymous with " $x$ and $A$ are phenomena" or " $x$ and $A$ are conscious" (in the intransitive sense of the term) or " $x$ and $A$ are subjectively experienced", and the like. In short: $x$ and $A$ are phenomena, appearances in the mind. More precisely: $x$ is a mental phenomenon, $A$ is a physical or mental phenomenon.

Obviously, the two conditions " $x$ appears" and " $A$ appears" are required as far as the goal is to provide a phenomenological definition of intentionality. Such a definition must at least satisfy the following two conditions. First, since intentionality is the definiendum, it must translate the intentional sentence into a sentence with no intentional verb. Second, the defining sentence is about nothing but phenomena, with their phenomenal properties and relations.

An obvious consequence of this is that the definition is trivially false if there exist unconscious representations. But Brentano, in his Psychology, holds unconscious representations to be a priori impossible. He provides a demonstration of that thesis but the matter is not of importance here.

Instead of " $x$ and $A$ appear”, we could also say " $x$ and $A$ are presented”. For Brentano gives only one definition of what a presentation is, and his definition is in terms of appearing. That something is presented, he says, means that it appears to one:

"As we use the verb 'to present', 'to be presented' means the same as 'to appear' (ist "vorgestellt werden” so viel wie "erscheinen”)." (Brentano, Psychologie vom empirischen Standpunkt, 1973: 114; Engl. transl. 81) 
"We speak of a presentation whenever something appears to us (Wir reden von einem Vorstellen, wo immer uns etwas erscheint).” (Brentano, Psychologie vom empirischen Standpunkt, 1874, 261; 1925, vol. 2, p. 34; Engl. transl. 198)

This point is of utmost importance because it is at the basis of what some interpreters construe as a self-representational theory of consciousness. At this stage, what Brentano's definition tells us is this: Whenever you represent something, you must have a presentation not only of the intentional content $A$, but of both an $x$ and an $A$. Both an $x$ and an $A$ must appear to you. In other words: your representation must have two distinct objects, namely $x$, which Brentano calls the "secondary object”, and A, which he calls the "primary object”.

\section{3. $x$ (really) exists, A does not (really) exist}

Let's now turn to the two clauses “ $x$ exists” (or “really exists”) and “ $A$ does not exist” (or “does not really exist”). Put otherwise: the mental phenomenon $x$ exists; the physical or mental phenomenon $A$, that is, the intentional object of $x$, does not exist.

"The objects of the so-called external perception (...) demonstrably do not exist outside of us. In contrast to that which really and truly exists, they are mere phenomena. (<Die> Gegenstände der sog. äussern Wahrnehmung (...) bestehen nachweisbar nicht ausser uns. Sie sind im Gegensatz zu dem, was wahrhaft und wirklich ist, blosse Phänomene).” (Brentano 1973: 14; Engl. transl. 10)

"Mental phenomena (...) are those phenomena which alone possess real existence as well as intentional existence. Knowledge, joy and desire really exist. Color, sound and warmth have only a phenomenal and intentional existence.” (Brentano 1973: 129; Engl. transl. 92) 
The overall idea is fairly intuitive. It is that appearing does not involve existing. Many things appear in your mind, and among them some exist, some do not. When you imagine Pegasus, what appears to you, what you experience, is both Pegasus and your imagining Pegasus. Pegasus does not need to exist for you to imagine Pegasus, actually it is a "mere appearance". But your imagining Pegasus must exist, otherwise you would not imagine Pegasus.

So, the difference is between things that appear and exist and things that appear and do not exist. However, it would be misleading to say that for Brentano this difference is equivalent to the difference between mental and physical phenomena. In fact, Brentano also claims that mental phenomena may exist intentionally and thus function as A's in definition (INT).

This idea is connected with Brentano's thesis that perceptual introspection is impossible. Introspection, he claims, is possible only in the mode of memory. It does not give one's own mental states as present, as perception does, but as past mental states. Brentano's example is well known: you cannot both feel angry and reflect on your anger at the same time, simply because reflection on anger causes you to cease to feel angry (Brentano 1973: 41; Engl. transl. 30). At the moment when you have an introspective representation of your own mental state, your mental state no longer exists. And what no longer exists does not exist at all.

To sum up: if you ask what exists for Brentano, the answer is: nothing except those mental phenomena which I experience right now. All the rest, namely physical phenomena and introspected mental phenomena, appear but do not really exist.

This clearly suggests that Brentano’s position in the 1874 Psychology is some special form of phenomenalism. Not merely a phenomenalism, as some interpreters have claimed, but more precisely a psychological variety of phenomenalism. Definition (INT) is phenomenalist because it implies that all $A$ 's, all objects of representation and thus all objects of knowledge, of physics as well as of psychology, are phenomena. But it also reflects a psychological variety of phenomenalism inasmuch as it ascribes existence only to present mental phenomena.

There are other reasons why Brentano's phenomenalism is different from the standard forms of phenomenalism such as the ones advocated by Mach and Avenarius, for example. The most significant difference, as it seems, has to do with the theory of intentionality itself. 
Let's return now to the so-called "problem of intentionality". This problem, or at least a version of it, is as follows: “... represents...” seems to be a relational predicate, but Pegasus does not exist and thus “ $x$ represents Pegasus” cannot denote any relation properly speaking.

What I said about the existence of mental phenomena according to Brentano clearly suggests one possible way out. To circumvent the problem of intentionality, we could simply opt for an adverbial approach to intentionality. We could say that the only things that really exist are my presently lived mental states with their phenomenal properties, and that being about something is just one of these properties. Accordingly, “... represents $A$ ” should be construed not as a relational, but as a one-place predicate.

Of course, once you construe “... represents $A$ ” as a one-place predicate, the so-called "problem of intentionality" ceases to be a problem at all. The intentional sentence " $x$ represents $A$ " is no more problematic than the sentence " $x$ is of such-and-such intensity" or " $x$ is of such-and-such psychological type". The sentence " $x$ represents $A$ ” is an extensional sentence which displays none of the puzzling logical features usually associated with the socalled "problem of intentionality”. It simply says that such-and-such mental state really exists, and that its psychological property of being about $A$ really exists, too, full stop.

Now, it is quite obvious that such a view would be highly unsatisfactory. Suppose I see an owl in the garden and describe it as I see it, say, as a brown bird with a flat face. I don't know if there really exists a physical substance corresponding to what appears in my mind — that's metaphysics. For the empirical scientist, the only existing thing in there is my mental state with its psychological property of being about the owl.

Now, it is clear that being brown and having a flat face cannot be construed as psychological properties. This would sound absurd. A mental state, obviously, cannot have a color or a flat face, it is not something it makes sense to ascribe spatial extension to. Yet it is really true that the owl looks brown, and the natural scientist is right to say that owls are generally brown.

In my view, it is to overcome this kind of problems that Brentano developed his theory of intentionality. The core idea is this. The psychologist talks about others' mental states, or about her past mental states. The physicist talks about colors, shapes, temperatures. None of these things really exist, they are mere appearances. Yet some physical or psychological theories are really true. So what makes them true if they are about mere appearances? Mere appearances do not exist and thus cannot make anything true! 
To this question, Brentano's answer is that the truthmaker and the intentional object are two different things. What a judgment about the owl is about is not what makes it true. In more contemporary words, we have to distinguish between intentionality and reference. On the one hand the judgment is about the owl and the owl does not really exist. On the other hand it refers to an existing object which makes it true - and this existing object is, once again, the representation of the owl, the mental state of which I am presently conscious.

As Brentano put it in the late 1880s, the owl is presented in modo obliquo as brown. The oblique mode corresponds to intentional aboutness. But the real reference, the existing object that is presented in modo recto, in a direct mode, is the present mental state with its psychological properties, including its property of being about the owl.

Hence there is a sense in which Brentano's theory of intentionality is an epistemological theory. Its purpose is to establish the possibility of empirical sciences, that is, of sciences whose objects are only mere phenomena. Brentano tries to demonstrate that a science can be true even if its objects are mere phenomena. And his solution is as follows: the empirical scientist can say true things about mere phenomena, but she ought to know that she actually refers only to present mental phenomena, for example to her remembering of the owl.

The empirical scientist's judgments rest upon oblique presentations, they are about mere appearances but actually refer to the scientist's real mental life. As Brentano puts it, the truth of scientific theories is just "relative truth", that is, not truth absolutely speaking, "in itself”, but truth for an experiencing subject:

“The truth of physical phenomena is (...) only a relative truth.” (Brentano 1973: 28;

Engl. transl. 19)

It is true that the owl is brown only if it is true in itself that there really exists an appearing of the brown owl. It is true relatively, say, for a subject $S$, that the owl is brown, it is absolutely true that a brown owl appears to $S$.

\section{4. $A$ appears in $x$}


We come now to the condition " $A$ appears in $x$ ". There is not much to say because the point is clear from what I have already said.

The general thought is that what happens when you see an owl is this: you are conscious of your perceiving, which is your real object, and you are conscious of something - a brown shape, a mere phenomenon - that appears “within” your perceiving and that does not exist. You may say, and even rightly say, that the owl is brown, but this is just an oblique way of saying that something really existing appears to you with something inexistent appearing in it. Intentionality in general is just a matter of “appearing in”. This is the very meaning of the word "content" as used by the Brentanians: something unreal appears, is phenomenally contained, within the real mental state you are conscious of.

As you see, this phrasing requires no intentional verb. Only appear words are required. Accordingly, the owl's being brown as well as the brown owl's being represented are purely phenomenological facts.

All this has direct implications for the epistemology of psychology. I will not delve into details here and confine myself to some general points.

The method of Brentano's psychology is a combination of introspection and analysis. First, the object of psychology is the flow of consciousness, thus something that is experienced in the first person. Secondly, Brentano adheres to a compositional view of mental life. On this view, the flow of consciousness is a whole composed of separable parts. As a consequence, the descriptive psychologist's task is to analyze this flow into its separable parts, the smallest of which are supposed to correspond to primitive concepts. On the one hand, the descriptive psychologist analyzes experiences into their elements; on the other hand she classifies them under basic concepts. For example, your aesthetic experience of a piece of music is a compound of an auditory presentation and a feeling of pleasure, and so on.

It is in this way that Brentano's intentionality thesis should be understood. The idea is that, however far one pushes psychological analysis, the ultimate elements obtained must necessarily be intentional acts. To put it otherwise: the smallest separable parts of the flow of consciousness are not mere sensory data, as standard phenomenalism claims. Rather, they must be mental phenomena with an intentional object appearing in them. 
Thus understood, the intentionality thesis entails that the intentional object cannot be a separable part of the mental state. Therefore, the mereological relation “... appears in...” in definition (INT) cannot denote a relation of composition properly speaking. The intentional object certainly is a part of the mental phenomenon, something that appears within it. But on the other hand it must be an inseparable part of it, in Brentano’s words: a “distinctional part”, that is, not a real, but a conceptual or abstract part.

\section{Conclusive remarks}

To some extent, it may seem that the picture of Brentano's theory of intentionality that emerges from my reading is of an old-fashioned introspectionist-phenomenalist epistemology with little or no contemporary relevance. However, I would like to conclude with five very sketchy remarks on some aspects of it which I hold as interesting and worth being taken seriously.

Firstly, whether one agrees or not with Brentano’s phenomenological approach to intentionality, it is less theoretically loaded than those in terms of biological functions, dispositions, or the like. Intentionality is not some sort of magical power in virtue of which what you experience inside relate to the outside world. It is just a feature of appearances, as are intensity or duration. As a result, the only assumptions required are, first, that things appear to one, and second, that some of them appear in such a way that in them something else appear whose existence is not required for them to appear.

Secondly, Brentano's approach suggests that there is no distinction to be made between experience and intentionality. In a sense, all you need is phenomenal experience, and this is why Brentano’s position is empiricism. This idea leads to a radical form of "inseparatism" which may be of interest in the current debate over cognitive phenomenology. Additionally, it is light years away from the semantic approach to intentionality, to which it is a genuine alternative.

In Brentano's view, intentionality in itself has nothing to do with concepts or propositions, or even with truth and falsehood, success and failure. Intentionality is a business of 
presentations, and presentations are not intrinsically capable of being true or false as are judgments. They are intrinsically no more than mere appearances: something appears or does not appear, no matter whether it really exists or not.

"Every presentation presents something, no matter whether it exists or not, no matter whether it appears as independent of us and forces itself upon our perception, or whether it is formed by us in our own imagination.” (Twardowski 1982: 36; Engl. trans. 33)

Thirdly, another advantage of phenomenologizing intentionality is that it allows a more natural formulation of the failures of entailment frequently associated with intentionality. For example, you may find it surprising that " $x$ represents $A$ " does not imply " $A$ exists”, or that " $x$ represents $A$ and $A$ is identical with $B$ " does not imply " $x$ represents $B$ ”. But there seems to be nothing odd about saying that " $A$ appears" does not imply " $A$ exists”, and that " $A$ appears and $A$ is identical with $B$ ” does not imply " $B$ appears".

Fourthly, the form of empiricism promoted by Brentano may seem, in some respects, more convincing than standard empiricism.

Like all forms of empiricism, Brentano’s empiricism asserts some relation of equivalence between subjective and objective statements, or between phenomena and reality. According to standard empiricism, for example standard phenomenalism or the sense-data theories, this means that all statement of the form " $\mathrm{x}$ is $\mathrm{P}$ " can and should be translated into a statement with an appear word, for example into a statement of the form "x looks P”, or "x appears to be P”, and so on. However, there are several difficulties with this relation of equivalence, and these difficulties are among the reasons philosophers like Chisholm, Sellars, and Austin rejected standard empiricism.

Now, Brentano’s variant of empiricism does not require us to translate objective into subjective statements or properties. Brentano's claim is not that talk of physical reality is misleading or illusory. For example, the zoologist is right to say that the owl is brown and her statement is really about physical reality. Being brown is a physical property, and Brentano, contrary to Mach, makes the difference between mental and physical properties. Physical theories may be true as theories about physical reality, but their truth is only relative, which means that they actually refer to mental life. Thus, there actually is a relation of equivalence between phenomena in mind and external reality. Both physics and psychology refer to the 
same thing, namely mental life, but both are about different things. Objective sciences are, so to speak, epistemologically autonomous, although they are dependent on subjective experience as to their referent or truthmaker.

Fifthly and finally, I think Brentano's theory of intentionality combines the advantages of a relational theory of intentionality with those of a non-relational theory of intentionality. All in all, what definition (INT) tells us is this: the grammar of intentional verbs suggests that the representation $x$ relates you to an object $A$, but actually $A$ is a mere intentional object, a mere appearance which does not exist, and thus intentionality itself is better seen as a merely apparent relation.

Katalin Farkas (2013) has proposed somewhere to construe intentionality as an "apparent directedness", and I think this is exactly what Brentano had in view when he characterized intentionality as a "mental relation”. Saying intentionality is an apparent relation is not saying that it is not a relation at all. There really appears to be a relation between $x$ and $A$. In other words: the relation holds not between an object $x$ and an object $A$, but between mere appearances, or between the letters " $x$ " and " $A$ " in the sentence " $x$ represents $A$ ", and so on.

\section{$\underline{\text { References }}$}

Brentano, F. (1874). Psychologie vom empirischen Standpunkte. Leipzig: Duncker \& Humblot.

Brentano, F. (1973). Psychologie vom empirischen Standpunkt. Hamburg: Meiner.

Brentano, F. (1925). Psychologie vom empirischen Standpunkt. Vol. 2: Von der Klassifikation der psychischen Phänomene. Leipzig: Meiner.

Byrne A. (2006). Intentionality. In: The Philosophy of Science: An Encyclopedia, S. Sarkar \& J. Pfeifer (Eds.). Vol. 1, p. 408-409.

Farkas K. (2013). Constructing a World for the Senses. In: Uriah Kriegel (ed.), Phenomenal Intentionality. Oxford University Press, pp. 99-115. 
Strawson G. (2010), Mental Reality. Cambridge MA: MIT Press, 2d edition with a new appendix.

Twardowski K. (1982). Zur Lehre vom Inhalt und Gegenstand der Vorstellungen: Eine psychologische Untersuchung. Wien: Philosophia Verlag. Eng. transl. On the Content and Object of Presentations (R. Grossmann). The Hague: M. Nijhoff, 1977. 